\title{
Determination of an Acceptable Portion Size of Daal for a Bangladeshi Community-Based Iron Intervention in Adolescent Girls: A Feasibility Study
}

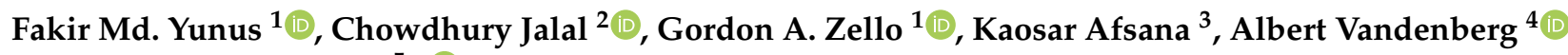 \\ and Diane M. DellaValle ${ }^{5, * \text { D }}$ \\ 1 College of Pharmacy and Nutrition, University of Saskatchewan, 104 Clinic Place, \\ Saskatoon, SK S7N 2Z4, Canada; fakir.yunus@usask.ca (F.M.Y.); gordon.zello@usask.ca (G.A.Z.) \\ 2 Nutrition International, 180 Elgin Street, Suite 1000, Ottawa, ON K2P 2K3, Canada; cjalal@nutritionintl.org \\ 3 James P Grant School of Public Health, BRAC University, 68 Shahid Tajuddin Ahmed Sharani, Mohakhali, \\ Dhaka 1212, Bangladesh; kaosar.afsana@bracu.ac.bd \\ 4 College of Agriculture and Bio-Resources, The University of Saskatchewan, Agriculture Building 51 Campus \\ Drive, Saskatoon, SK S7N 5A8, Canada; bert.vandenberg@usask.ca \\ 5 Department of Sports Medicine, King's College, 133 N River St, Wilkes-Barre, PA 18711, USA \\ * Correspondence: dianedellavalle@kings.edu
}

\section{check for}

updates

Citation: Yunus, F.M..; Jalal, C.; Zello, G.A.; Afsana, K.; Vandenberg, A.; DellaValle, D.M. Determination of an Acceptable Portion Size of Daal for a Bangladeshi Community-Based Iron Intervention in Adolescent Girls: A Feasibility Study. Nutrients 2021, 13, 1080. https://doi.org/10.3390/ nu13041080

Academic Editors: James H. Swain and Roberto Iacone

Received: 5 February 2021

Accepted: 24 March 2021

Published: 26 March 2021

Publisher's Note: MDPI stays neutra with regard to jurisdictional claims in published maps and institutional affiliations.

Copyright: (c) 2021 by the authors. Licensee MDPI, Basel, Switzerland. This article is an open access article distributed under the terms and conditions of the Creative Commons Attribution (CC BY) license (https:/ / creativecommons.org/licenses/by/ $4.0 /)$.

\begin{abstract}
Widely consumed daal (lentils) in Bangladesh are an ideal vehicle for iron (Fe) fortification; however, an acceptable portion size in meals needs to be determined to carry out a community feeding study in at-risk adolescent girls. A non-randomized crossover trial was conducted with $n=100$ Bangladeshi girls (12.9 \pm 2.0 years of age). Two recipes (thin and thick) and three portion sizes ( $25 \mathrm{~g}, 37.5 \mathrm{~g}$, $50 \mathrm{~g}$ of raw lentil) of daal were served with $250 \mathrm{~g}$ of cooked white rice in a counterbalanced manner over 12 weeks. Each meal was fed to participants 5 days/week for two weeks. Ratings of hunger, satiety, and palatability were measured before and after each meal using Visual Analog Scales (VAS). The thick preparation in the $37.5 \mathrm{~g}$ portion ( $200 \mathrm{~g}$ cooked) elicited higher VAS ratings of hunger, satiety, and palatability compared to all other meals. The $50 \mathrm{~g}$ portion of the thin preparation had VAS ratings similar to those of the $37.5 \mathrm{~g}$ thick preparation. Consuming the $37.5 \mathrm{~g}$ portion of fortified daal would provide $6.9 \mathrm{mg}$ Fe/day to girls in a community-based effectiveness study. This would meet $\sim 86 \%$ and $\sim 46 \%$ of the Recommended Dietary Allowance (RDA) for Fe for girls aged $9-13$ and $14-18$ years, respectively.
\end{abstract}

Keywords: lentils; fortification; iron; adolescent girls; portion size; feeding study; Bangladesh; crossover trial; feasibility

\section{Introduction}

Iron deficiency anemia (IDA) is the most widespread nutritional deficiency in the world [1]. Annual deaths directly linked to IDA are around 24,000 globally and have been steadily increasing since 2000 [2]. The WHO 2011 report suggested that approximately 25\% of the global population ( 1.6 billion) were suffering from anemia, and preschool children and women of reproductive age contributed the major portion of this global burden [1]. In Bangladesh, a nationally representative survey (2013) reported that anemia prevalence (hemoglobin $<12.0 \mathrm{~g} / \mathrm{dL}$ ) was $26 \%$ among non-pregnant non-lactating women and 17\% adolescents aged 12-14 years [3]. Also IDA prevalence (hemoglobin $<11.5 \mathrm{~g} / \mathrm{dL}$ and ferritin $<5.0 \mu \mathrm{g} / \mathrm{L}$ ) was $1.3 \%$ among children $6-11$ years of age and $1.8 \%$ among adolescents aged 12-14 years [3]. However, iron deficiency (ID) prevalence without anemia (hemoglobin $>12 \mathrm{~g} / \mathrm{dL}$ and serum ferritin $<15.0 \mu \mathrm{g} / \mathrm{L}$ ) was reported to be slightly higher than anemia prevalence, i.e., $7.1 \%$ among non-pregnant non-lactating women and $9.5 \%$ among children aged 12-14 years. Several other studies have recommended Fe fortification as a preferable choice to reduce IDA [4-6]. In a systemic review, studies found that hemoglobin 
significantly increased among women of reproductive age due to the consumption of Fe-fortified foods [7].

We hypothesized that fortifying lentil (Lens culinaris Medik) with Fe could be a potential long-term sustainable solution to combat global ID and IDA among adolescent girls. We chose lentil because it is a widely consumed staple food in Bangladesh and it has a high nutrient density [8]. Furthermore, several studies have recommended lentil as a potential food vehicle for fortification because of its low content of anti-Fe absorption compounds (e.g., phytate) and high content of Fe, even pre-fortification [9-11]. A community-based human effectiveness trial, however, is warranted to estimate the effectiveness of Fe-fortified lentil on the improvement of body iron status. We expect that food-based supplemental Fe from Fe-fortified lentils will improve body Fe status. To carry out such a trial, several crucial aspects needed to be addressed, including the portion size of the lentil meal, the frequency and duration of feeding, participants' acceptability of different portion sizes, and cooking preparation of the lentil meal to be consumed. Therefore, the objective of the current feasibility study was to determine an acceptable portion size of a lentil meal for adolescent girls' daily consumption, which was critical prior to designing a large-scale community-based effectiveness trial.

\section{Materials and Methods}

\subsection{Study Setting and Population}

Adolescent girls (10-17 year) who were members of Bangladesh Rural Advancement Committee (BRAC) Adolescent Clubs were invited to participate in the current study. BRAC is a multi-national non-government organization (NGO) that was ranked number one among non-governmental organizations in the world for the fifth consecutive year till 2020 [12]. One of its developmental programs is designed for adolescents, providing a platform and opportunity to socialize both in rural and in urban settings. Adolescent boys and girls can be members regardless of school attendance, marital or pregnancy status, or economic standing. Around $25-40$ adolescents participate in a club, and clubs run 2 days per week in the evenings. The current feasibility study purposively chose 4 adolescent clubs of 2 upazilas (sub-districts of Sreepur and Tongi Pouroshava municipalities) of the Gazipur district. These clubs were chosen because they were well functioning with good attendance of adolescent girls. While this study targeted adolescent girls, we served the daal meal to all boys and girls who were members of BRAC adolescent clubs and who were willing to consume the meals. No one declined to consume the meal, and there was no exclusion criterion for participation. As per the study objectives, however, data were collected only from adolescent girls. No adolescent girls declined to participate or were excluded from the study for any other reason.

\subsection{Study Design and Trial}

A crossover trial was carried out with $n=100$ adolescent girls aged $10-17$ years. Those girls who were active members of a BRAC adolescent club and were aged between 10 and 17 years were included in the study. We served 2 different cooking preparations or recipes (thin and thick) of daal (a lentil meal) and 3 different portion sizes (equal to raw amounts of $25 \mathrm{~g}, 37.5 \mathrm{~g}$, and $50 \mathrm{~g}$ of lentils) for 12 weeks (Figure 1). These portion sizes were decided based on the amount of Fe that could potentially be delivered within those portion sizes over the longer community trial. 


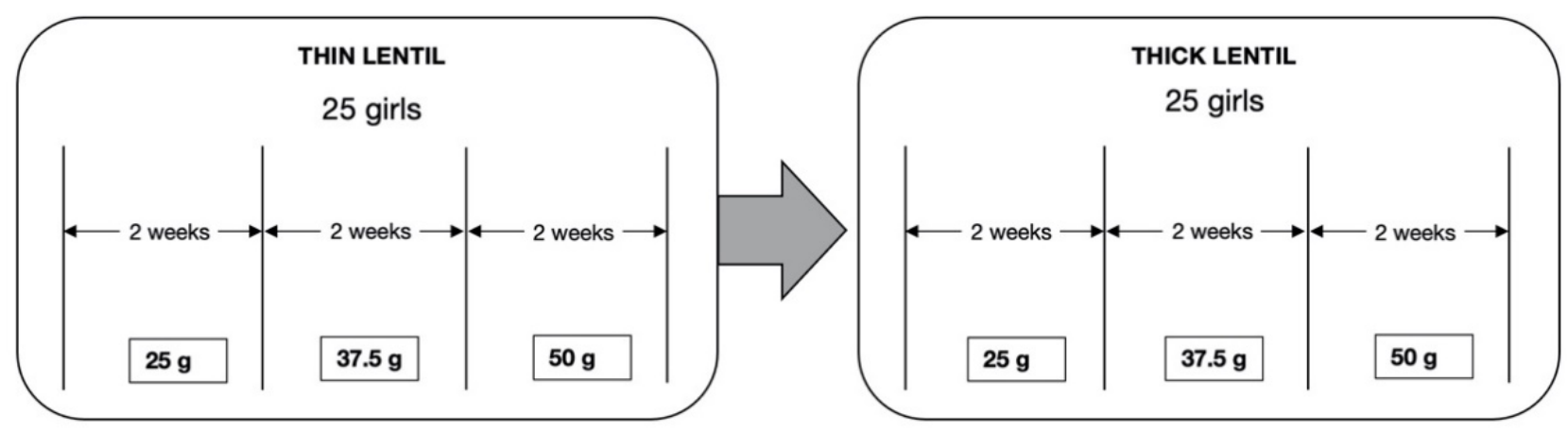

Figure 1. Cross-over design of the study that included 25 adolescent girls in each club $(4$ clubs $\times 25$ adolescent girls $=100$ adolescent girls).

Due to the nature of the crossover study design, each adolescent girl served as her own control. Referring to previous food intake studies, a sample size of $n=100$ adolescent girls was our target [13]. A total of $n=100$ adolescent girls were enrolled from the four adolescent clubs $(n=25$ girls participated from each club). Standardized recipes were used for each of the six conditions, with the basic daal recipe being locally derived (Table 1). Cooks were recruited from local neighbourhoods adjacent to each of the respective adolescent clubs and trained for this study. They completed cooking in a local kitchen under the close supervision of trained research assistants.

Table 1. Recipes of thick and thin preparations of iron-fortified lentils.

\begin{tabular}{|c|c|c|c|c|}
\hline \multirow[t]{2}{*}{ S1. No } & \multicolumn{2}{|c|}{$\begin{array}{l}\text { Thick Lentil Cooking Preparation and Amount } \\
\text { (Based on } 100 \mathrm{~g} \text { of Uncooked Daal) }\end{array}$} & \multicolumn{2}{|c|}{$\begin{array}{l}\text { Thin Lentil Cooking Preparation and Amoun } \\
\text { (Based on } 100 \mathrm{~g} \text { of Uncooked Daal) }\end{array}$} \\
\hline & Ingredients & Amount (g) & Ingredients & Amount (g) \\
\hline 1 & Daal & 100 & Daal & 100 \\
\hline 2 & Turmeric & 5 & Turmeric & 3 \\
\hline 3 & Chopped onion & 40 & Chopped onion & 40 \\
\hline 4 & Garlic & 8 & Garlic & 8 \\
\hline 5 & Green chili & 3 smalls & Green chili & 3 smalls \\
\hline 6 & Water & $700 \mathrm{~mL}$ & Water & $1.5 \mathrm{~L}$ \\
\hline 7 & Salt & 1.5 teaspoonful & Salt & 1.5 teaspoonful \\
\hline 8 & Soyabean oil & 10 teaspoonfuls & Soyabin oil & 6 teaspoonfuls \\
\hline 9 & Bay Leaf (Tejpata) & 1 (small) & Bay Leaf (Tejpata) & 1 (small) \\
\hline \multirow[t]{2}{*}{10} & Time & $18 \mathrm{~min}$ & Time & $53 \mathrm{~min}$ \\
\hline & \multicolumn{2}{|c|}{ Weight after cooking: $585 \mathrm{~g}$} & \multicolumn{2}{|c|}{ Weight after cooking: $1166 \mathrm{~g}(1.166 \mathrm{Kg})$} \\
\hline
\end{tabular}

Each adolescent girl was served 1 portion of each daal preparation (thin $25 \mathrm{~g}$, thin $37.5 \mathrm{~g}$, thin $50 \mathrm{~g}$, thick $25 \mathrm{~g}$, thick $37.5 \mathrm{~g}$, and thick $50 \mathrm{~g}) 5$ days a week for 2 weeks. Each portion size of daal was served with 1 cup of cooked polished local white rice $(\sim 250 \mathrm{~g})$, since daal is not usually eaten without cooked rice in Bangladesh. These meals were served as late afternoon snacks in the BRAC adolescent clubs, between 4 and $6 \mathrm{pm}$. At first, the thin preparation of $25 \mathrm{~g}$ was served, followed by thin $37.5 \mathrm{~g}$, thin $50 \mathrm{~g}$, thick $25 \mathrm{~g}$, thick $37.5 \mathrm{~g}$. and thick $50 \mathrm{~g}$ (Figure 2). Iron fortification was carried out at the Crop Development Centre (CDC) of the University of Saskatchewan, Canada. Small cotyledon lentils were chosen because of their naturally high content of iron compared to other available lentils (Podder et al., 2017). Lentils were fortified with $16 \mathrm{ppm}$ NaFeEDTA Fe fortificant/100 g lentils, sprayed as a fine mist, which was absorbed through a polishing drum at a commercial lentil mill located in Saskatoon, Canada. Details of the iron fortification have been described previously $[14,15]$. 


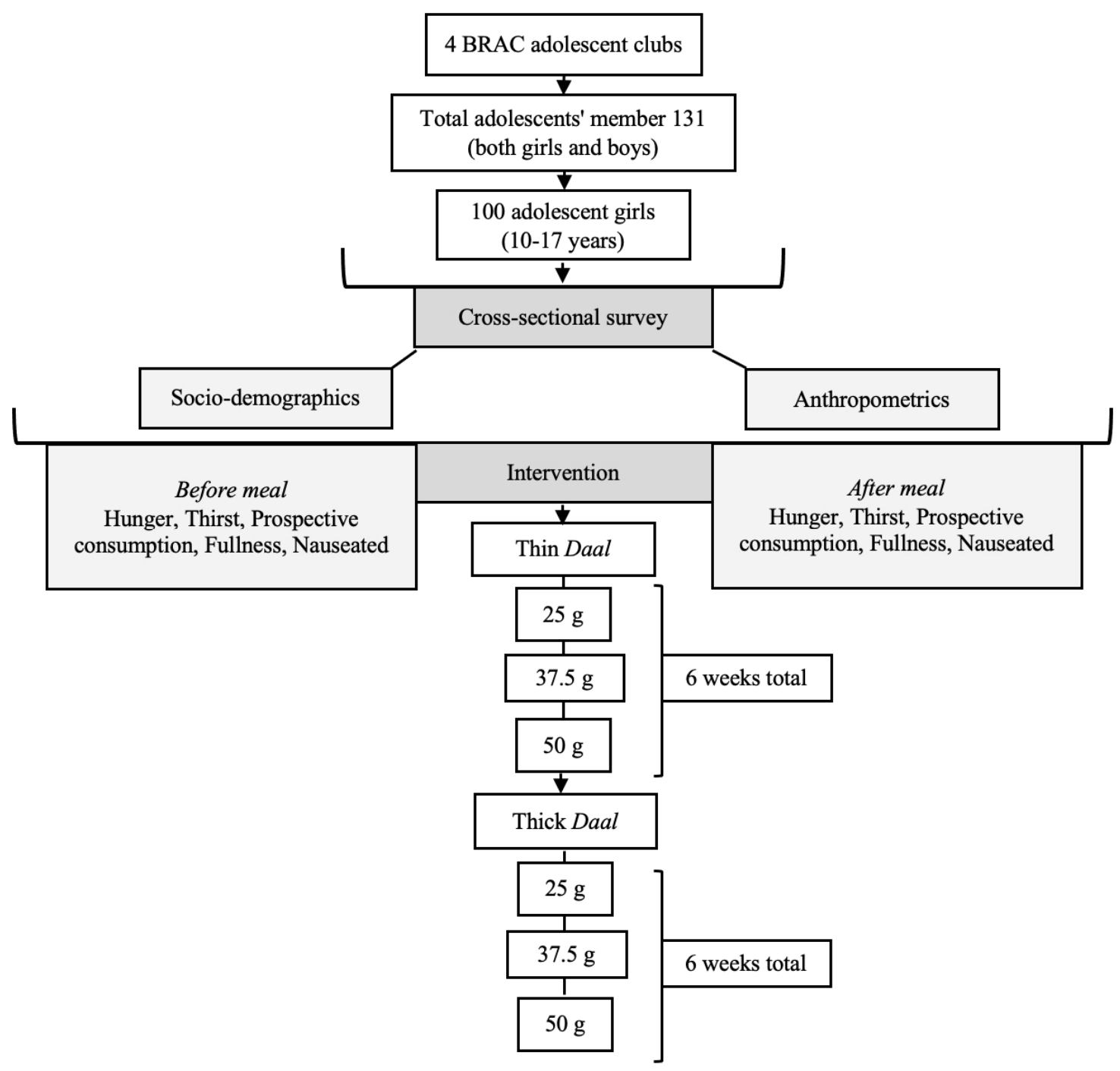

Figure 2. Study profile. BRAC, Bangladesh Rural Advancement Committee.

\subsection{Study Variables and Outcome Measurements}

Survey data were collected by trained research assistants. At first, adolescent girls and their respective parents/guardians were informed separately by the study research assistants on the purpose of the study, data collection process, risks and benefits of participating in the study and were asked to sign the informed written consent and assent form with the presence of a witness. Once both of the parties signed the forms (consent and assent), a copy of both documents were given to them. Detailed demographic information was collected via face-to-face interviews, and anthropometric measurements were taken using standardized methods and guidelines [16-19].

Subjective ratings of hunger, fullness, thirst, nausea, prospective consumption, and sensory characteristics were obtained before and after consumption of each daal meal, using paper-based Visual Analog Scales (VAS). VAS are a well-accepted tool that captures subjective attitudes or characteristics for which the probable response lies within a range of values that cannot be directly or easily captured [20]. This measurement tool is commonly used in human feeding studies for measuring hunger, thirst, prospective consumption, fullness, and nausea [21-24].

Portion sizes (grams) of each daal meal were measured before and after consumption of each daal meal using a \pm 1 g precision rechargeable digital scale (MEGA Super; Reg: (Dhaka) No 128005). The residual amount of daal was also recorded. Cooked rice was 
not weighed, but rather served in a standard weight $(1 \mathrm{c}=250 \mathrm{~g})$ and mixed with cooked daal (cooked rice is locally known as baat). The estimated consumed iron was calculated, referring to the iron content of $50 \mathrm{~g}$ of raw lentils indicated in a previous study [14]. The study reported $10 \mathrm{mg}$ of iron present in $50 \mathrm{~g}$ of raw lentils, of which 3-3.5 mg from lentils and $6.5-7 \mathrm{mg}$ from the iron fortificant.

\subsection{Statistical Analysis}

Data were analyzed with SPSS Statistics for Mac, version 25 (SPSS Inc., Chicago, IL, USA) using a mixed linear model and repeated measures ANOVA (RMANOVA). We used RMANOVA for daal intake (in grams) and each of the VAS ratings (in mm) of hunger, thirst, prospective consumption, feeling full, and feeling nauseated to compare before and after consuming the six preparations (thin $25 \mathrm{~g}$, thin $37.5 \mathrm{~g}$, thin $50 \mathrm{~g}$, thick $25 \mathrm{~g}$, thick $37.5 \mathrm{~g}$, and thick $50 \mathrm{~g}$ ). We used a linear mixed model to examine the consumption of each of the six preparations of daal, with the fixed effect of served daal (cooked amount), in order to determine the effect of the served daal on girl's consumption (in grams), with the random effect of upazila. The interaction of these 2 factors was tested for significance before examination of the main effects. A modified Bonferroni procedure was used for post-hoc pairwise comparisons of the means. Results were considered significant at $p<0.05$.

\section{Results}

The demographic characteristics of the sample are presented in Table 2. In total, data from $n=100$ girls were analyzed, and we experienced no dropouts during the 12-week feeding trial, with only $5.2 \%$ of meals being missed by the adolescents. Mean $( \pm S D)$ age and body mass index (BMI) were $12.9 \pm 0.9$ years and $17.1 \pm 3.0 \mathrm{~kg} / \mathrm{m}^{2}$, respectively, and the majority of the participants $(64 \%)$ reported a regular menstrual cycle.

Table 2. Characteristics of the participants $(n=100)$.

\begin{tabular}{ll}
\hline Variables & Adolescent Girls (Age 10-17 Years) \% \\
\hline Age (mean \pm SD) & $12.9 \pm 2.0$ \\
Age of menarche (mean \pm SD) & $12.1 \pm 0.9$ \\
Menstruation (Yes) & 64 \\
Menstrual regularity (once every month) & 54 \\
Marital status (No) & 97 \\
Education (Secondary) & 67 \\
Socioeconomic status & 52 \\
House wall (Brick/Cement) & 95 \\
House roof (Tin) & 82 \\
House floor (Brick/Cement) & 98 \\
Electricity & $146.8 \pm 10.0$ \\
Anthropometric & $37.3 \pm 9.2$ \\
Height; cm (mean \pm SD) & $64.9 \pm 7.0$ \\
Weight; kg (mean \pm SD) & $78.1 \pm 7.9$ \\
Waist circumference; cm (mean \pm SD) & $20.8 \pm 3.2$ \\
Hip circumference; cm (mean \pm SD) & $17.1 \pm 3.0$ \\
Mid-upper arm circumference (MUAC); & \\
cm (mean \pm SD) & \\
Body mass index (BMI) &
\end{tabular}




\subsection{Differences in Preference by Cooking Preparation}

Hunger, thirst, and prospective consumption were found significantly when comparing the thin and the thick preparations of daal, both before and after the meal (Figure 3). However, the mean score of the prospective consumption was significantly lower for the thick daal preparations compared to the thin meal preparations.

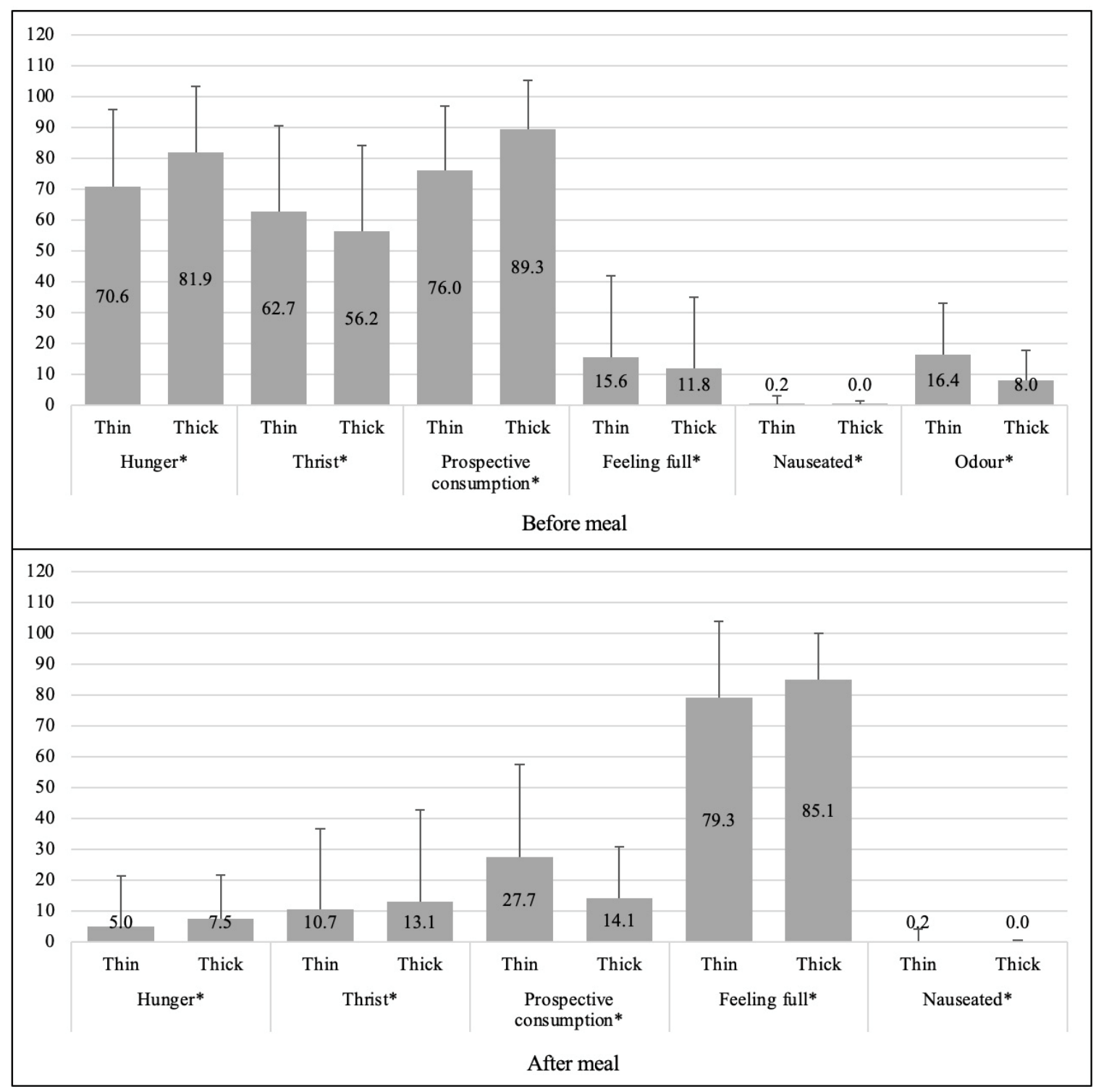

Figure 3. Mean \pm SD differences of Visual Analog Scales (VAS) variables between thick and thin daal preparations before and after the meals $(\mathrm{N}=100)$. Ratings of VAS scores: $0-100 \mathrm{~mm}$, highest score = extremely happy, lowest score $=$ not at all happy. The difference of VAS scores between thin and thick preparations of daal before and after the meals shows that in relation to thin and thick daal, preferences were significantly different for all VAS variables. This means adolescent girls had different preference in regard to thin and thick preparations of daal with respect to the parameters hunger, thirst, prospective consumption, feeling full, and feeling nauseated. * Independent sample $t$ test significant at $p<0.05$.

\subsection{Difference in Preference by Portion Size}

Significant differences were found in regard to the different portion sizes before and after daal consumption (Figure 4). We observed lower prospective consumption ratings corresponding to the bigger portion sizes, and higher ratings of fullness corresponding to the larger portion sizes. 


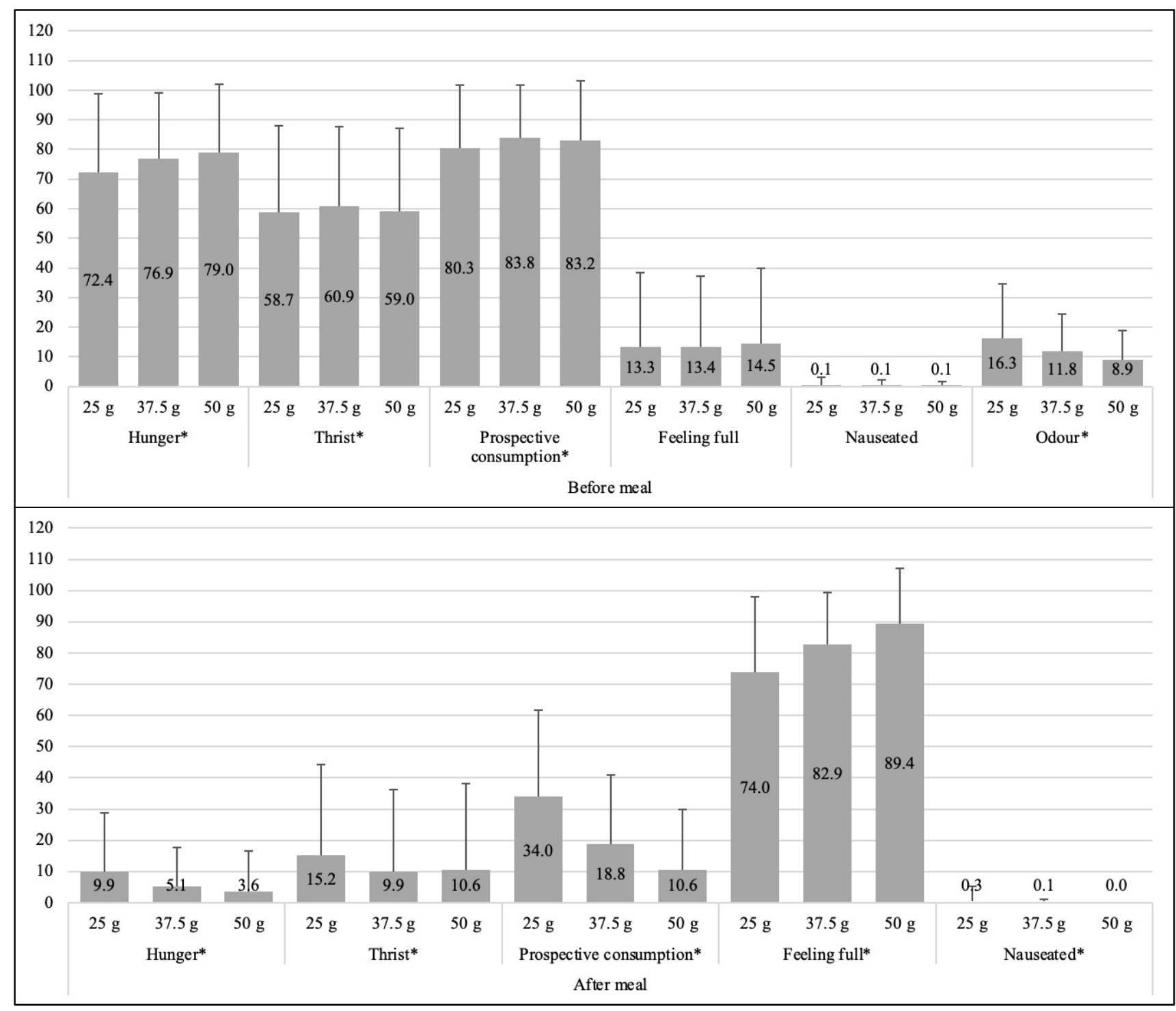

Figure 4. Mean \pm SD differences of VAS variables among portion sizes before and after the meals $(\mathrm{N}=100)$. Ratings of VAS scores: 0-100 mm, highest score = intense, lowest score = not at all intense. Differences of VAS scores for $25 \mathrm{~g}$, $37.5 \mathrm{~g}$, and $50 \mathrm{~g}$ of daal before and after the meals shows that preference for different portion sizes significantly differed with respect to each VAS variable. This means adolescent girls had different preferences for $25 \mathrm{~g}, 37.5 \mathrm{~g}$, and $50 \mathrm{~g}$ of daal with respect to the parameters of hunger, thirst, prospective consumption, feeling full, and feeling nauseated. * One-way ANOVA test significant at $p<0.001$.

\subsection{Difference in Preferences by Combined Portion Size and Cooking Preparation}

Significant differences were observed for all six preparations of different size: condition 1 (thin $25 \mathrm{~g}$ raw lentils), condition 2 (thin $37.5 \mathrm{~g}$ raw lentils), condition 3 (thin $50 \mathrm{~g}$ raw lentils), condition 4 (thick $25 \mathrm{~g}$ raw lentils), condition 5 (thick $37.5 \mathrm{~g}$ raw lentils), and condition 6 (thick $50 \mathrm{~g}$ raw lentils) before and after the meals (Figure 5). Before meal, the thick $37.5 \mathrm{~g}$ raw lentils recorded the highest prospective consumption rating, and after meal, the thick $37.5 \mathrm{~g}$ raw lentils had the second-lowest prospective consumption rating. 


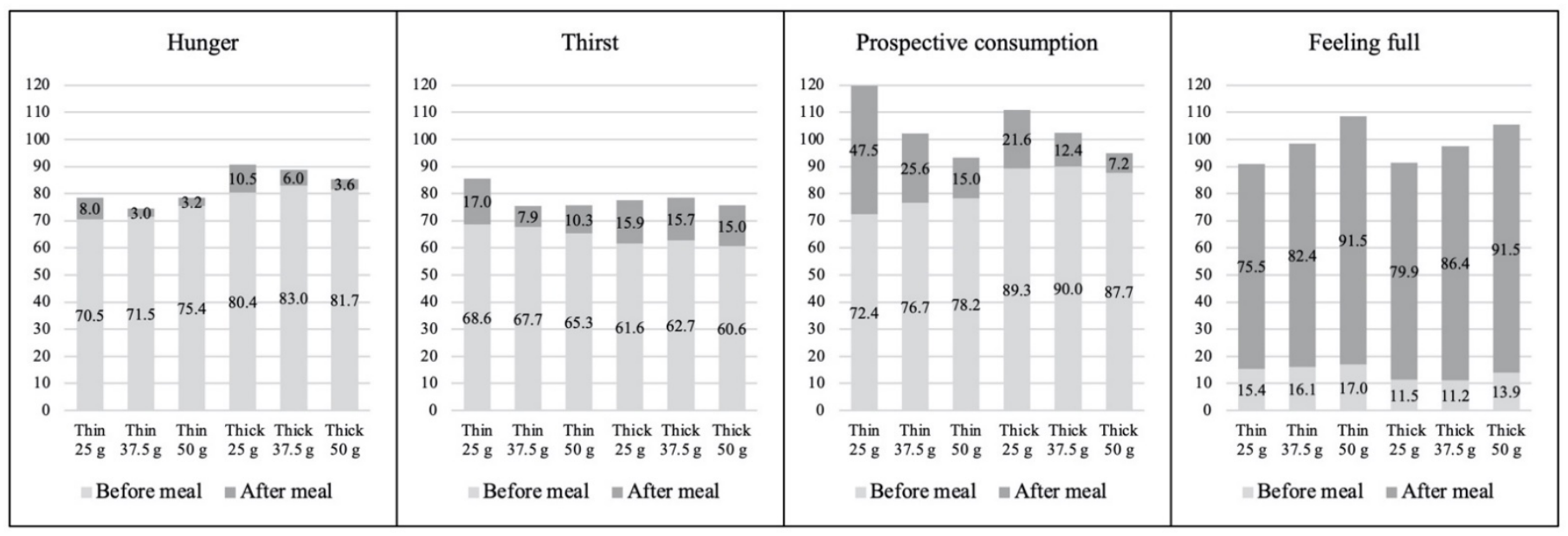

Figure 5. Difference in preferences in relation to the six portion sizes. Repeated measures ANOVA and post-hoc test with Bonferroni correction were used to assess significant differences for hunger after meal for the six preparations of cooked lentils: condition 1 (thin $25 \mathrm{~g}$ raw lentils), condition 2 (thin $25 \mathrm{~g}$ raw lentils), condition 3 (thin $50 \mathrm{~g}$ raw lentils), condition 4 (thick $25 \mathrm{~g}$ raw lentils), condition 5 (Before meal thick $37.5 \mathrm{~g}$ raw lentils), and condition 6 (thick $50 \mathrm{~g}$ raw lentils). Shown are significant differences of VAS scores for the six conditions of daal before and after the meals. Among all significant differences, we noted condition 5 (before meal, thick $37.5 \mathrm{~g}$ raw lentils) had the highest mean hunger score, followed by condition 6 (before meal, thick $50 \mathrm{~g}$ raw lentils). Condition 5 (before meal, thick $37.5 \mathrm{~g}$ raw lentils) had the highest prospective consumption score, followed by condition 4 (before meal, thick $25 \mathrm{~g}$ raw lentils). However, condition 12 (after meal, thick $50 \mathrm{~g}$ raw lentil) had the lowest prospective consumption score, followed by condition 11 (after meal, thick $37.5 \mathrm{~g}$ raw lentils). Condition 9 (after meal, thin $50 \mathrm{~g}$ raw lentils) and condition 12 (after meal. thick $50 \mathrm{~g}$ ) had the highest score for sense of feeling full, followed by condition 11 (after meal, thick $37.5 \mathrm{~g}$ raw lentils).

\subsection{Residual Amount and Estimated Iron Intake}

Differences in portion size, consumed amount, residual amount, and estimated iron content of the consumed amount for all six conditions are presented in Table 3. We found that high values for portion size ended with the higher consumption, and the higher residual amount regardless of the cooking preparation. Significantly lower residual amounts $(4.8 \pm 12.4 \mathrm{~g}, 17.7 \pm 29.6 \mathrm{~g}$, and $27.1 \pm 45.9 \mathrm{~g}$ for $25 \mathrm{~g}, 37.5 \mathrm{~g}$, and $50 \mathrm{~g}$ of thick daal, respectively) were observed for all thick daal preparations compared to $\mathrm{f}$ thin daal (29.1 \pm 44.0 , $36.5 \pm 55.3$, and $61.9 \pm 79.9$ for $25 \mathrm{~g}, 37.5 \mathrm{~g}$, and $50 \mathrm{~g}$ of thin daal, respectively). This indicates higher consumption of thick preparations compared to thin preparations. The mixed model suggested that the portions of served daal (cooked) corresponding to thin $37.5 \mathrm{~g}$, thin $50 \mathrm{~g}$, thick $25 \mathrm{~g}$, and thick $50 \mathrm{~g}$ significantly affected girl's daal consumption; however, the served amount of thin daal of $25 \mathrm{~g}$ and of thick daal of $37.5 \mathrm{~g}$ did not significantly influence their consumption.

Table 3. Mean \pm SEM differences for all conditions regarding served, residual, consumed daal meals and estimated iron consumption.

\begin{tabular}{|c|c|c|c|c|}
\hline $\begin{array}{l}\text { Consumption Daal } \\
\text { Conditions }\end{array}$ & Served Daal (g) & Residual Daal (g) & $\begin{array}{l}\text { Consumed Daal } \\
\text { (Cooked Amount) (g) }\end{array}$ & $\begin{array}{l}\text { Iron Contents in } \\
\text { Consumed Daal }\end{array}$ \\
\hline Thin $25 \mathrm{~g}$ & $274.2 \pm 2.2 *$ & $29.0 \pm 4.4 * \Psi$ & $245.0 \pm 4.9 *$ & $4.5 \pm 0.01 *$ \\
\hline Thin $37.5 \mathrm{~g}$ & $331.6 \pm 1.5^{*}$ & $36.2 \pm 5.5 * \Psi$ & $294.8 \pm 6.3 *$ & $6.7 \pm 0.1 * \Psi$ \\
\hline Thin $50 \mathrm{~g}$ & $431.2 \pm 1.6^{*}$ & $61.5 \pm 8.1 *$ & $369.2 \pm 8.2 *$ & $8.6 \pm 0.1 * \Phi$ \\
\hline Thick $25 \mathrm{~g}$ & $157.9 \pm 0.7^{*}$ & $4.9 \pm 1.2 *$ & $153.1 \pm 1.6^{*}$ & $4.9 \pm 0.0 *$ \\
\hline Thick $37.5 \mathrm{~g}$ & $202.7 \pm 1.5^{*}$ & $17.5 \pm 3.0 *$ & $185.2 \pm 2.4^{*}$ & $6.9 \pm 0.1 * \Psi$ \\
\hline Thick $50 \mathrm{~g}$ & $256.4 \pm 1.9 *$ & $27.1 \pm 4.6 * \Psi$ & $229.3 \pm 4.5^{*}$ & $9.0 \pm 0.2 * \Phi$ \\
\hline
\end{tabular}

${ }^{*}$ Pairwise comparison with Bonferroni adjusted post-hoc analysis, significant at $p<0.001 ;{ }^{\Psi}$ and ${ }^{\Phi}$ Not significant; ${ }^{* *} 50 \mathrm{~g}$ of fortified raw lentil $=10 \mathrm{mg}$ of iron after cooking [14]. 


\section{Discussion}

We conducted a feasibility study to identify an acceptable portion size of Fe-fortified lentils and the preferred cooking preparation to be used in a community-based effectiveness trial [15]. We observed lower residual amounts of the thick preparations of daal compared to the thin preparations. The teen girls preferred the thick daal to the thin one and said they could eat more of it; consequently, they consumed more lentil from this less-soupy, thick preparation in a lower volume.

Determining the feasible daal portion size that could be consumed in a month-long trial is not straightforward. Age, current lentil consumption, iron recommended dietary allowance (RDA), and Fe bioavailability of the used lentils are major factors in determining the portion size to serve for effect size calculations and implementation for Fe interventions. For instance, age plays an important role in determining the necessary Fe intake because of the different daily Fe requirements by age groups. The RDA of Fe for girls aged 9-13 years is $8 \mathrm{mg}$ /day, plus additional $2.5 \mathrm{mg} /$ day for those who have started to menstruate and $15 \mathrm{mg} /$ day for girls aged $14-18$ years [25]. Around $50 \%$ of our study population was aged 10-12 years, which means that for half of the population, the RDA was $8.0 \mathrm{mg} /$ day plus an additional $2.5 \mathrm{mg} /$ day for the girls who had started to menstruate. We categorized our study population into two age groups: 10-13 years and 14-18 years, based on the age-specific RDAs for iron.

Considering the estimated daily iron intake, $4.5-4.9 \mathrm{mg}$ iron from a thick/thin $25 \mathrm{~g}$ portion-size of daal provided an estimated $61.2 \%$ of the RDA for Fe for girls aged between 10 and 13 years (based on the $8 \mathrm{mg}$ RDA for Fe) and 32.6\% of the RDA for Fe for girls 14-18 years old (based on the $15 \mathrm{mg}$ RDA for Fe). This additional Fe intake from the iron-fortified lentils may not be sufficient for girls 14-18 years of age, since it only covers one-third of their daily iron RDA. The $37.5 \mathrm{~g}$ (thick/thin) portion size provided $6.7-6.9 \mathrm{mg}$ of $\mathrm{Fe}$, which covered approximately $86 \%$ (and $65.7 \%$ for those who had started to menstruate) of the RDA for Fe for adolescent girls aged 9-13 years and $46 \%$ of the RDA for Fe for girls aged 14-18 years. An estimated 8.6-9 mg Fe was ingested from a $50 \mathrm{~g}$ (thick/thin) meal, which exceeded the RDA for Fe set for younger girls aged $10-13$ years ( $8 \mathrm{mg} /$ day).

The $50 \mathrm{~g}$ portion of the thin preparation had VAS ratings similar to those of the $37.5 \mathrm{~g}$ thick preparation. However, considering the age-specific RDA for Fe and consumed Fe, the $37.5 \mathrm{~g}$ portion size was considered reasonable for an effectiveness trial. An additional argument in favor of the $50 \mathrm{~g}$ portion size is that it provides an amount of iron equal to or slightly higher than the RDA for Fe, and Fe has high Tolerable Upper Intake Levels (ULs) for girls aged $9-13$ years $(40 \mathrm{mg})$ and $14-18$ years $(45 \mathrm{mg})$ [25].

Before making a conclusion on a reasonable portion size, it is necessary to evaluate the relative Fe bioavailability of the portion of lentil considered suitable. While lentils are a plant source of non-heme iron, fortifying lentil with NaFeEDTA increases Fe absorption by $79 \%$ and significantly reduces the absorption of Fe inhibitor compounds, such as phytic acid [26]. Additionally, we chose dehulled lentils for Fe fortification, because an earlier study reported that lentil seed coat removal increases the relative Fe bioavailability [27]. This is because ferric iron has the highest binding stability with EDTA (ethylene diamine tetra-acetic acid) and EDTA thus protects from binding to iron absorption inhibitors [28,29].

Since we experienced no dropouts over 12 weeks, this may mean that teen girls in this area are likely to continue to consuming fortified daal in similar settings; however, the small number of participants $(n=100)$ was easy to retain over 12 weeks within the four BRAC clubs, possibly because of the close monitoring of the study participants by the study research assistants and their regular connection with the adolescent girls. Furthermore, BRAC, which organizes the adolescent clubs, is an NGO accepted by the community. Uncertainty exists with regard to how adolescents might behave in other contexts and to studies with a larger number of participants (e.g., $n=1200$ ). In regard to the diet of rural Bangladeshi adolescent girls, seven-day food frequency data reported that fish, meat, eggs, and lentils were consumed, on average, 3.4, 0.6, 1.1, and 1.7 days out of 7 days, respectively [30]. We could find detail dietary intakes of lentil by adolescent girls in 
Bangladesh; however, an earlier study reported that the average consumption of pulses in Bangladesh is $12 \mathrm{~g} /$ day/person [31].

We provided a standard small cup ( $250 \mathrm{~g}$ ) of cooked rice (locally known as baat) to all intervention conditions because, culturally, daal is usually consumed with baat; however, since each subject served as her own control, any fluctuation of any one participant's daal consumption due to baat would have likely affected equally all conditions.

A major strength of the study is the design, as all subjects were equally exposed to all interventions, and each participant served as her own control. We served daal meals 5 days per week and considered 2 days as a "wash-out" period, since there could have been the chance to observe a 'carry-over effect' if we fed the girls 7 days per week. Additionally, we used standardized recipes. One of the major limitations of the study was that the order of the intervention conditions (thin $25 \mathrm{~g}$, thin $37.5 \mathrm{~g}$, thin $50 \mathrm{~g}$, thick $25 \mathrm{~g}$, thick $37.5 \mathrm{~g}$, and thick $50 \mathrm{~g}$ ) was not randomly assigned or counter-balanced to the four adolescent clubs. Since we used the convenience sampling technique, generalizability cannot be applied. We did not collect information about other factors that may influence ID, which could be useful for future trials, but this feasibility study was not designed to examine those variables. Furthermore, the girls consumed $86-89 \%$ and $90-97 \%$ of the served thin and thick daal, respectively; this may mean that their prior dietary intake during the day may have influenced this high consumption.

\section{Conclusions}

In conclusion, a portion size of $37.5 \mathrm{~g}$ of raw lentil in a thick cooking preparation using a local recipe was acceptable to adolescent girls aged 10-17 years; therefore, a communitybased effectiveness trial could be carried out over a longer period of time to examine the effect of this amount of daal on iron status.

Author Contributions: Conceptualization, D.M.D., C.J., G.A.Z. and A.V.; investigation, D.M.D., C.J., G.A.Z., K.A. and F.M.Y.; analysis, F.M.Y., D.M.D. and C.J.; writing-original draft preparation, F.M.Y., D.M.D. and C.J.; writing—review and editing, F.M.Y., D.M.D., C.J., A.V., G.A.Z. and K.A. All authors have read and agreed to the published version of the manuscript.

Funding: This research was funded by Global Institute for Food Security (GIFS), University of Saskatchewan, Canada.

Institutional Review Board Statement: The study was conducted according to the guidelines of the Declaration of Helsinki and approved by the Research Ethics Board of The University of Saskatchewan (Bio\#15-162 and 21 July 2016), Marywood University (Ref\# 2015-025 and 22 August 2016), USA and BRAC University James P Grant School of Public Health (JPGSPH), Bangladesh (Ref\#73 and 12 June 2016).

Informed Consent Statement: Informed consent was obtained from all subjects involved in the study.

Data Availability Statement: Corresponding author may be contacted by qualified researchers for data sharing. All aspects of ethical issues and existing data sharing policies will be reviewed before sharing data.

Acknowledgments: We would like to sincerely thank our BRAC colleagues Raisul Huq, Shabukta Malik, Mamun Mia, Enamul Huq, Mafijul Islam, and Mahfuzar Rahman for their support in data collection. We express our sincere appreciation to Rajib Podder, College of Agriculture and Bioresource at the University of Saskatchewan for fortifying lentils with iron. We sincerely acknowledge the support from the BRAC Research and Evaluation Division's field implementation and data collection team. We thank Shawna Bieber, Crystal Chan, and Brent Barlow for their support in organizing and supporting the study. Special thanks to Shannon Hood-Niefer, Sara Lui, and Aaron Pidskalny from Saskatchewan Food Industry Development Centre Inc. Saskatoon, Saskatchewan, Canada for their support in the lentil fortification program.

Conflicts of Interest: The authors declare no conflict of interest. 


\section{References}

1. World Health Organization. The Global Prevalence of Anaemia in 2011; World Health Organization: Geneva, Switzerland, 2011.

2. World Health Organization. Global Health Estimates 2018: Disease Burden by Cause, Sex, by Country and Region, 2000-2016; World Health Organization: Geneva, Switzerland, 2018.

3. ICDDRB; UNICEF Bangladesh; GAIN; Institute of Public Health and Nutrition. National Micronutrients Status Survey 2011-12: Final Report; ICDDRB: Dhaka, Bangladesh, 2013.

4. Miller, J.L. Iron deficiency anemia: A common and curable disease. Cold Spring Harb. Perspect. Med. 2013, 3. [CrossRef]

5. Thavarajah, D.; Thavarajah, P.; Sarker, A.; Vandenberg, A. Lentils (Lens culinaris medikus subspecies culinaris): A whole food for increased iron and zinc intake. J. Agric. Food Chem. 2009, 57, 5413-5419. [CrossRef]

6. Thavarajah, D.; Thavarajah, P.; Wejesuriya, A.; Rutzke, M.; Glahn, R.P.; Combs, G.F.; Vandenberg, A. The potential of lentil (Lens culinaris L.) as a whole food for increased selenium, iron, and zinc intake: Preliminary results from a 3 year study. Euphytica 2011, 180, 123-128. [CrossRef]

7. Das, J.K.; Salam, R.A.; Kumar, R.; Bhutta, Z.A. Micronutrient fortification of food and its impact on woman and child health: A systematic review. Syst. Rev. 2013, 2, 1. [CrossRef]

8. Erskine, W.; Sarker, A.; Kumar, S. Crops that feed the world 3. Investing in lentil improvement toward a food secure world. Food Secur. 2011, 3, 127-139. [CrossRef]

9. Beyer, P.; Al-Babili, S.; Ye, X.; Lucca, P.; Schaub, P.; Welsch, R.; Potrykus, I. Golden Rice: Introducing the beta-carotene biosynthesis pathway into rice endosperm by genetic engineering to defeat vitamin A deficiency. J. Nutr. 2002, 132, 506S-510S. [CrossRef]

10. Lucca, P.; Hurrell, R.F.; Potrykus, I. Fighting iron deficiency anemia with iron-rich rice. J. Am. Coll. Nutr. 2002, 21, 184S-190S. [CrossRef]

11. Ye, X.; Al-Babili, S.; Klöti, A.; Zhang, J.; Lucca, P.; Beyer, P.; Potrykus, I.; Sommer, A.; West, K.P.; Howard, G.R.; et al. Engineering the Provitamin A ( $\beta$-Carotene) Biosynthetic Pathway into (Carotenoid-Free) Rice Endosperm. Science 2000, 287, 96-305. [CrossRef] [PubMed]

12. BRAC. BRAC Ranked Top Global NGO of 2018. Available online: http://www.brac.net/latest-news/item/1145-brac-rankedtop-global-ngo-of-2018 (accessed on 5 July 2018).

13. Dibari, F.; Bahwere, P.; Huerga, H.; Irena, A.H.; Owino, V.; Collins, S.; Seal, A. Development of a cross-over randomized trial method to determine the acceptability and safety of novel ready-to-use therapeutic foods. Nutrition 2013, 29, 107-112. [CrossRef] [PubMed]

14. Podder, R.; Tar'an, B.; Tyler, R.; Henry, C.; DellaValle, D.M.; Vandenberg, A. Iron fortification of lentil (lens culinaris medik.) to address iron deficiency. Nutrients 2017, 9, 863. [CrossRef] [PubMed]

15. Yunus, F.M.; Jalal, C.; Afsana, K.; Podder, R.; Vandenberg, A.; DellaValle, D.M. Iron-fortified lentils to improve iron (Fe) status among adolescent girls in Bangladesh—Study protocol for a double-blind community-based randomized controlled trial. Trials 2019, 20, 251. [CrossRef]

16. 'Lohman, T.; 'Roche, A.; 'Martorell, R. Anthropometric Standardization Reference Manual; Human Kinetics: Champaign, IL, USA, 1988.

17. Bacopoulou, F.; Efthymiou, V.; Landis, G.; Rentoumis, A.; Chrousos, G.P. Waist circumference, waist-to-hip ratio and waist-toheight ratio reference percentiles for abdominal obesity among Greek adolescents. BMC Pediatr. 2015, 15. [CrossRef]

18. World Health Organization. Physical Status: The Use and Interpretation of Anthropometry; World Health Organization: Geneva, Switzerland, 1995.

19. National Health and Nutrition Examination Survey (NHANES). Anthropometry Procedures Manual; NHANES: Atlanta, GA, USA, 2007.

20. Wewers, M.E.; Lowe, N.K. A critical review of visual analogue scales in the measurement of clinical phenomena. Res. Nurs. Health 1990, 13, 227-236. [CrossRef] [PubMed]

21. Flint, A.; Raben, A.; Blundell, J.E.; Astrup, A. Reproducibility, power and validity of visual analogue scales in assessment of appetite sensations in single test meal studies. Int. J. Obes. 2000, 24, 38-48. [CrossRef]

22. Parker, B.A.; Sturm, K.; MacIntosh, C.G.; Feinle, C.; Horowitz, M.; Chapman, I.M. Relation between food intake and visual analogue scale ratings of appetite and other sensations in healthy older and young subjects. Eur. J. Clin. Nutr. 2004, 58, 212-218. [CrossRef]

23. Sadoul, B.C.; Schuring, E.A.H.; Symersky, T.; Mela, D.J.; Masclee, A.A.M.; Peters, H.P.F. Measuring satiety with pictures compared to visual analogue scales. An exploratory study. Appetite 2012, 58, 414-417. [CrossRef] [PubMed]

24. Lindeman, A.; Huang, M.; Dawkins, E. Using the Visual Analog Scale (VAS) to measure perceived hunger and satiety at various mealtimes and environments. J. Acad. Nutr. Diet. 2016, 116, A99. [CrossRef]

25. Institute of Medicine. Dietary Reference Intakes; National Academies Press: Washington, DC, USA, 2003 ; ISBN 0309091322.

26. Podder, R.; DellaValle, D.M.; Tyler, R.T.; Glahn, R.P.; Tako, E.; Vandenberg, A. Relative bioavailability of iron in Bangladeshi traditional meals prepared with iron-fortified Lentil Dal. Nutrients 2018, 10, 354. [CrossRef] [PubMed]

27. DellaValle, D.M.; Glahn, R.P. Differences in relative iron bioavailability in traditional Bangladeshi meal plans. Food Nutr. Bull. 2014, 35, 431-439. [CrossRef] 
28. Ginanjar, E.; Indrawati, L.; Setianingsih, I.; Atmakusumah, D.; Harahap, A.; Timan, I.; Marx, J. Iron absorption in iron-deficient women, who received $65 \mathrm{mg}$ Fe with an Indonesian breakfast, is much better from NaFe(III)EDTA than from Fe(II)SO4, with an acceptable increase of plasma NTBI. A randomized clinical trial. Pharmaceuticals 2018, 11, 85. [CrossRef] [PubMed]

29. Dueik, V.; Chen, B.K.; Diosady, L.L. Iron-polyphenol interaction reduces iron bioavailability in fortified tea: Competing complexation to ensure iron bioavailability. J. Food Qual. 2017, 2017. [CrossRef]

30. Alam, N.; Roy, S.K.; Ahmed, T.; Ahmed, A.M.S. Nutritional status, dietary intake, and relevant knowledge of adolescent girls in rural Bangladesh. J. Heal. Popul. Nutr. 2010, 28, 86-94. [CrossRef] [PubMed]

31. Sarker, A.; Erskine, W.; Abu, M.; Matiur, B.M.; Afzal, R.M.A.; Saxena, M.C. Lentil Improvement in Bangladesh: A Success Story of Fruitful Partnership between the Bangladesh Agricultural Research Institute and International Center for Agricultural Research in the Dry Areas; Asia-Pacific Association of Agricultural Research Institutions (APAARI): Bangkok, Thailand, 2004; Available online: http://www.apaari.org/web/wp-content/uploads/2009/05/ss_2004_01.pdf (accessed on 4 September 2020). 